\title{
THE DETERMINANTS OF ONLINE SHOPPING: BUILDING COMMUNICATION WITH CUSTOMERS IN AN ONLINE DIMENSION
}

\author{
Elina Radionova-Girsa ${ }^{1}$, mag.soc/ doctoral student; Anda Batraga ${ }^{2}$, dr.oec. and Jelena \\ Salkovska ${ }^{3}$, dr.oec. \\ $1,2,3$ University of Latvia
}

\begin{abstract}
Nowadays customers increase using the Internet environment to make their purchases. It helps them not only to save time and money, but makes the whole process more efficient. However, marketing on the Internet and outside it has some similarities, and it interacts with customers.

The authors of this article analyse communication with the customers on the Internet. The result is analysed and the key trends are highlighted that are currently outlined in communication with customers. In addition, the authors of the article look at the marketing communication on the Internet as part of their overall marketing strategy.

The aim of the paper - to find out and analyse determinants of online shopping in order to increase marketing communication effectiveness on the Internet.

Methods - theoretical analysis of literature, conducting customers' surveys and statistical analysis.

The results showed the strong influence of social networks for marketing communications in the Internet environment, this is explained by the fact that in the Internet there is No traditional personal service. The results have theoretical as well as practical significance.
\end{abstract}

Key words: marketing communication, online shopping, customer behaviour, marketing strategy. JEL code: M31.

\section{Introduction}

Being all the time in a competitive market, companies have to adapt to their customers, their needs and desires. Selling goods in the traditional market, the trader is accustomed to the use wellknown and proven marketing communication to be able to reach consumers and guide them to buy a product, as well as to return and become regular customers. Since the first advertising on the Internet on 1994 (Cook, 2016), the Internet has changed very rapidly and dynamically, thus significantly affecting the marketing communication. For example, today particularly important among researchers is marketing communication in social networks, which have currently a large impact on how consumers could be encouraged.

In the Internet environment, the consumer has a unique opportunity to move quickly between offers and shops, to look for alternatives and the best options that can satisfy one's wishes as good as possible. However, it is assumed that the consumer needs to evaluate the product only on the information provided by the trader on the website, namely, image, description, another consumer feedback, etc. It should be noted that the overall appearance of the website and how easy it is to navigate the website when searching for the product and its specification is also important for the consumer when making the purchase decision. In essence, the consumer sees only a picture with a description, from which consumer has to draw conclusions and make a decision on making a purchase. Perhaps the consumer will look for some feedback, ask for help from relatives and friends, but the first impression on the website is the first impression on consumer. Of course, it is not at all to say that if at the end the consumer receives a product that is not suiTable for the image and description, one will not only be dissatisfied, but also the trust of the particular Internet marketer will be low and there is No desire to buy something again.

\footnotetext{
${ }^{1}$ Email:elinaradionova@gmail.com

2 Email: anda.batraga@lu.Iv

3 Email: jelena.salkovska@lu.Iv
} 
This is important not only for selling products, but also for online services such as hotel reservations, airline tickets, bank services. In this case, the interaction will also be with the device itself and the home page. The better the website design and the more convenient navigation, the more satisfied the consumer will be in the purchasing process. The authors fully agree that it is necessary for the consumer to feel comforTable and free on the website so that the interaction on the Internet is as easy as possible and the consumer would not only want to return to this Internet merchant and make repeated purchases, but also recommend this site to one's relatives and friends.

Consumers are searching on the Internet for two different types of activities - hedonic and utilitarian shopping. Hedonic shopping is focused on the entertainment process from the use of the website, such as virtual tours, pictures etc. In turn, utilitarian shopping is geared towards the end result - a purchase that was made to achieve a specific goal, such as price comparison, finding a better service location etc. The main difference between these directions is that with hedonic shopping, the consumer gets entertainment, satisfaction and pleasure through the use of the Internet, but in a utilitarian case one has a specific goal to be achieved in the purchasing process. Hence, website owners need to adapt their site to both categories of consumers, both those looking for entertainment and those who have a specific goal to find everything they need there.

The main utilitarian features can be the availability, the ability to effectively search for the necessary information, the provision of full product or service information. For consumers looking for utilitarian features, site designers need to provide informative design with ease and ease of use. In contrast, hedonic peculiarities are such as joy, entertainment, fantasy, advancement to the purchase. Therefore, creators need to use moving (animated) images, pay close attention to colour selection, sound, social component and aesthetic appearance. Hedonic features also include game features to motivate the consumer to visit the website several times because of gambling.

The authors emphasize that the need to understand what type of consumer is in front of vendor, because it is consumer's knowledge to be able to communicate successfully with the vendor. Without a doubt, you can make your website so comforTable and enjoyable to have both categories, but sometimes entertaining content is difficult to fit in the specific nature of the industry websites, so it is necessary for some type of consumer orientation.

The aim of the paper - to find out and analyse determinants of online shopping in order to increase marketing communication effectiveness on the Internet.

Main tasks of the research are to analyse theoretical literature and the data from statistical sources and data received from the survey. Survey was compiled for the next study as a pilot survey, so the interim results are currently collected. The survey is created and distributed by authors using the Internet facilities - social networks. The first phase of the survey took place between December 2018 and January 2019. Authors received 312 responses, which are valid for analysis.

Methods - theoretical analysis of literature, conducting customers' surveys and statistical analysis.

The results showed the strong influence of social networks for marketing communications in the Internet environment, this is explained by the fact that in the Internet there is No traditional personal service, which is an important factor in the traditional trade. The results have theoretical as well as practical significance.

\section{Research results and discussion}

In Ab Hamid and McGrath study (Ab Hamid, McGrath, 2005), 12 dimensions of Internet communication have been identified, those dimensions affect the effectiveness of online marketing 
strategy: information quality, design, customer service, transaction execution conditions, integrated marketing channels, online communities, bonuses, personalization levels, website security, added customer value, reliability and price advantage. However, Mekkamol, Piewdang, and Untachai (Mekkamol et al., 2013) developed and tested the validity and reliability of four factors. They found a positive link between shopping convenience, the nature of the website, the dimensions of care and services, and the interactivity of website contacts. The authors agree that all these factors are important, but want to highlight the personalization that is available in online stores. Considering that there are many other influencing factors in the literature such as alternatives and time-saving (Lee et al., 2017), website design and its characteristic (Hasan, 2016), previous experience and trust during the whole purchase process (Kawaf, Tagg, 2017), the authors of the paper would like to emphasize that it is important to understand what exactly their consumers need when designing communication companies. Therefore, a model is presented below (Fig. 1), which shows the communication cycle on the Internet.

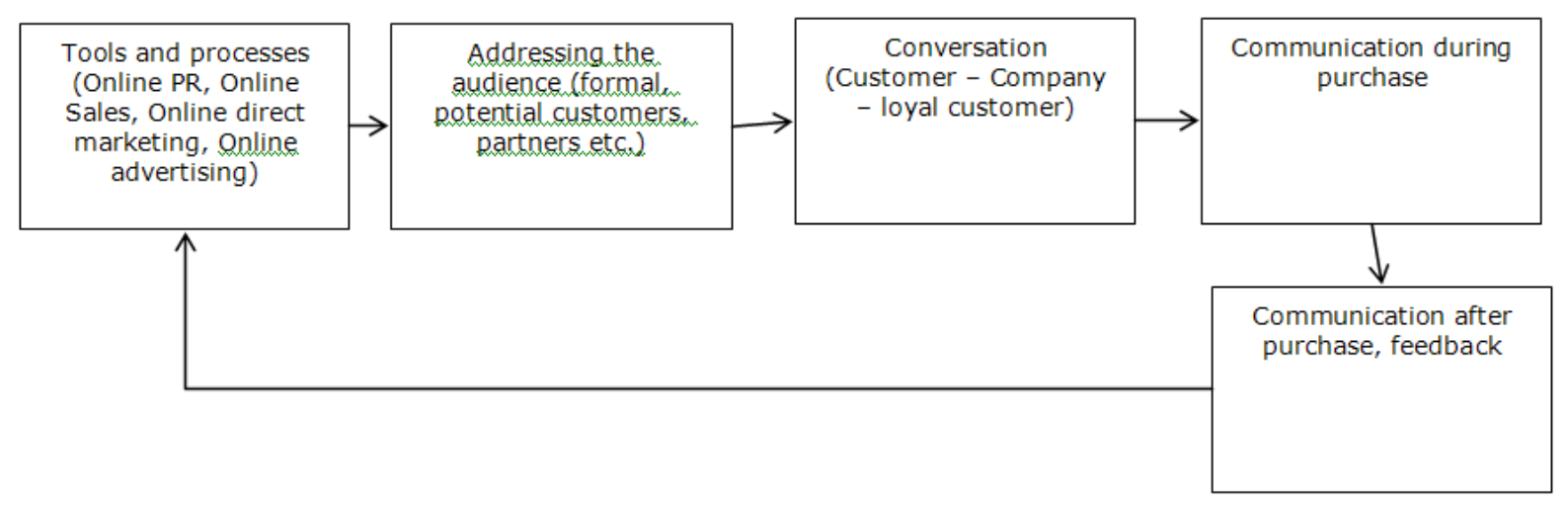

Source: authors created based on Semeradova, Vavrova, 2016

Fig. 1. Internet communication cycle

In the first audience process, the inputs are divided into four marketing communication categories: online public relations, online marketing, online sales promotion, online advertising. Using online tools such as websites, social networks and networks, portals, advertising and search marketing tools, enterprises share business and marketing data with their target audience (Semeradova, Vavrova, 2016). The authors of the paper point out that they chose this model because they believe that communication at each stage and through different channels is important in the Internet shopping process. In turn, choosing the most appropriate communication is possible when it is understood what exactly the customer wants.

\section{European online shopping tendencies}

According to Eurostat data in 2018, there were $69 \%$ of European citizens that ordered goods or services online. The higher tendency for online shopping is in the United Kingdom (87\%), Denmark (86 \%), Sweden (84\%), the Netherlands (84\%) and Germany (82\%). In the Baltic States, the results are: $54 \%$ in Lithuania, $53 \%$ in Latvia and $68 \%$ in Estonia. The results show that most people make purchases on the Internet. Therefore, the authors want to find out how these purchases are made. Fig. 2 shows the specifics of consumer behaviour before making a purchase online in the EU (28 countries) and the three Baltic States. 
Individuals did not buy/order online by clicking/buying straightaway through an advertisement on a social media website or app Individuals bought/ordered online by clicking/buying straightaway through an advertisement on a social media website or app Individuals used customer reviews on websites or blogs rarely or never before buying/ordering online

Individuals used price or product comparison websites or apps rarely or never before buying/ordering online

Individuals used information from several retailer, producer or service provider websites rarely or never before buying/ordering online

Individuals used customer reviews on websites or blogs some times before buying/ordering online

Individuals used price or product comparison websites or apps some times before buying/ordering online

Individuals used information from several retailer, producer or service provider websites some times before buying/ordering online

Individuals used customer reviews on websites or blogs every time or almost every time before buying/ordering online

Individuals used price or product comparison websites or apps every time or almost every time before buying/ordering online

Individuals used information from several retailer, producer or service provider websites every time or almost every time before...

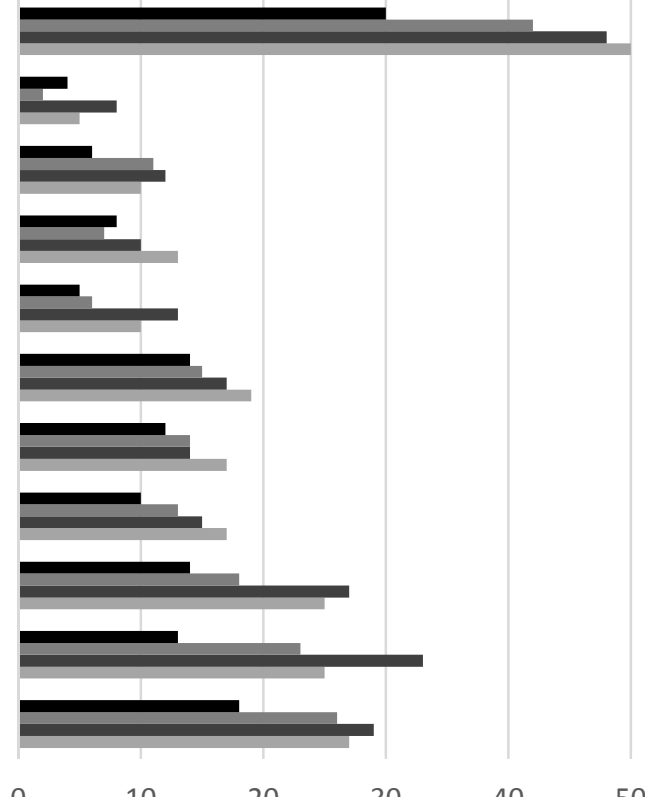

- Lithuania Latvia Estonia European Union - 28 countries

Source: Eurostat (online code: isoc_ec_ibhv)

Fig. 2. Consumers' behaviour related to online purchases ( $\%$ )

Fig. 2 shows that before making a purchase on a website, the consumer uses the information available on the websites of different merchants, or uses the recommendations of friends or follows the recommendations of other buyers. This indicates that when there are so many different options, it is difficult for the consumer to choose right away. That's why it's important to talk to consumers and build a dialogue with them. Next, the authors of the paper propose to review the most important data obtained from the survey.

\section{Collected data review}

Authors made a pilot survey, so the interim results are currently collected. The survey is created and distributed by authors using the Internet facilities - social networks, random selection took place. The first phase of the survey took place between December 2018 and January 2019. Authors received 312 responses, which are valid for analysis. According to Gemius research data, more than $70 \%$ of Internet users do online shopping. However, in 2018 there were $86 \%$ of Latvian population that used Internet at least once per year. 


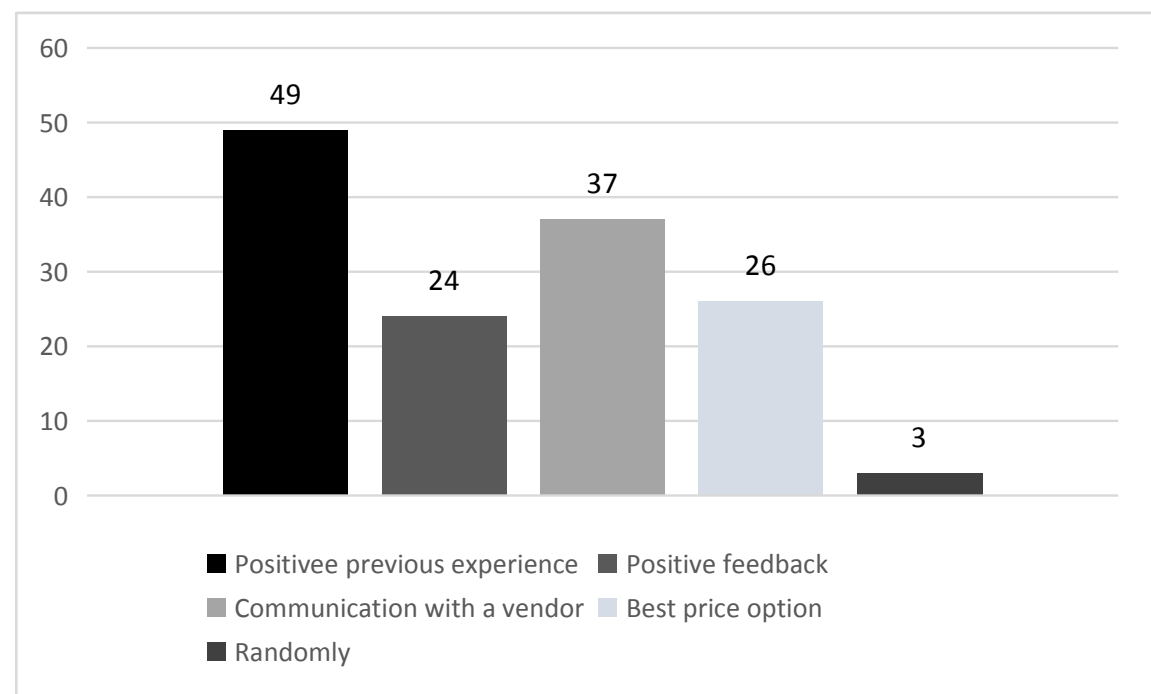

Source: authors' construction based on survey data

Fig. 3. Criteria for Internet merchant selection ( $\%$ of respondents)

In turn, as it can be seen in Fig. 3, an important factor in shopping at a particular merchant is a positive previous experience ( $49 \%$ of respondents). Further, respondents point out communication with the vendor, which should be positive and easy (37\%). And in third place consumers have placed positive feedback ( $24 \%$ of respondents) pointing to the link with social media.

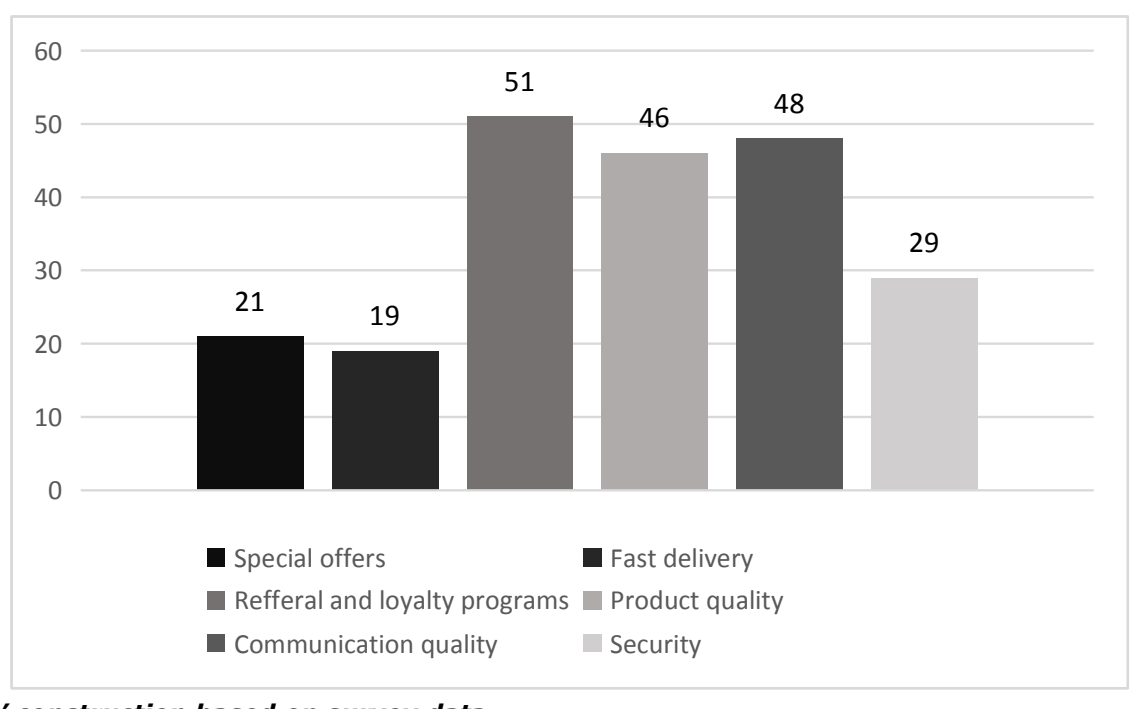

Source: authors' construction based on survey data

Fig. 4. Criteria to recommend a vendor to friends and acquaintances ( $\%$ of respondents)

Authors point out that consumers are ready to recommend an online store if they benefit from it - bonus points, loyalty points etc. (51\%). But communication with the merchant and the quality of this communication ( $48 \%$ ) are also important, in addition to quality of the product ( $48 \%$ ). So, this indicates that communication that is well-targeted and personalized really improves the consumer's interest and thoughts on the company. 


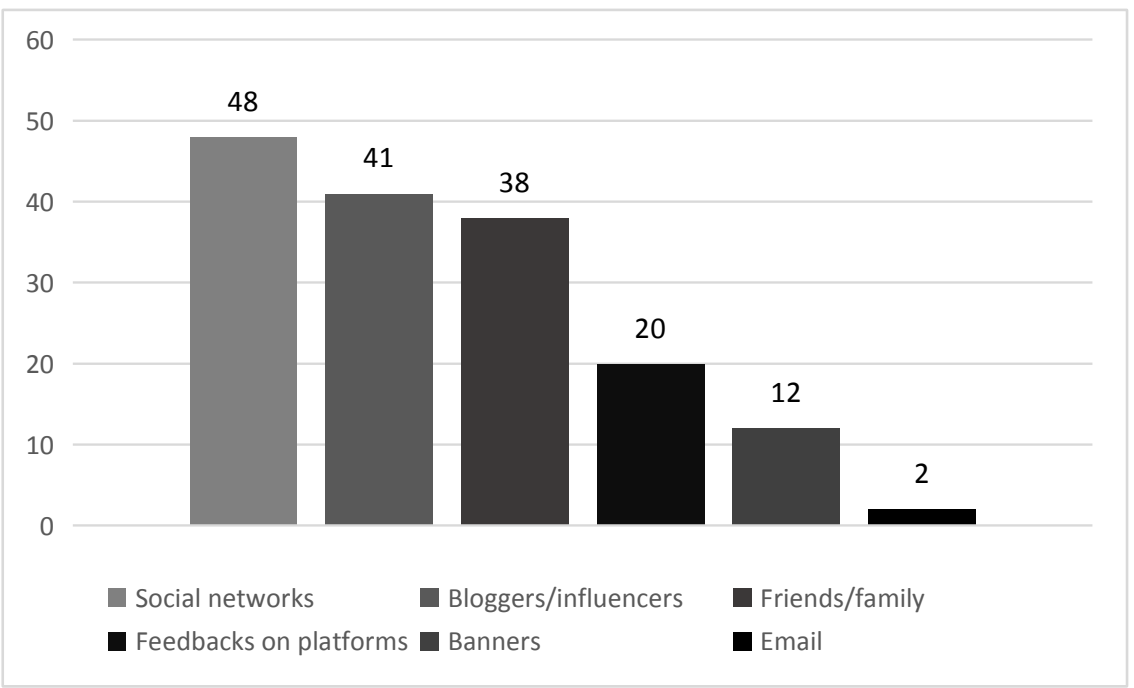

Source: authors' construction based on survey data

Fig. 5. How customers are attracted to the online shop ( $\%$ of respondents)

One of the questions was how the consumer is attracted to a particular online store. The authors wanted to find out what kind of communication better addresses the consumer and directs to the store. As it can be seen from Fig. 5, customers are more likely to visit particular online store through social networks (48 \%) and that's not a secret that a lot of vendors communicate with their audience there in their social web-pages or in specially made groups. Also, bloggers and influencers (41\%) can promote an online shop to customers and after their videos, posts or vlogs (video blogs) customers visit promoted shop or platform. And, of course, it should be posted out that friends (38\%) as well can be like a promoter, because there is a connection and trust. Authors found out an interesting thing that neither banners, nor emails stimulate customers to attend a particular online shop.

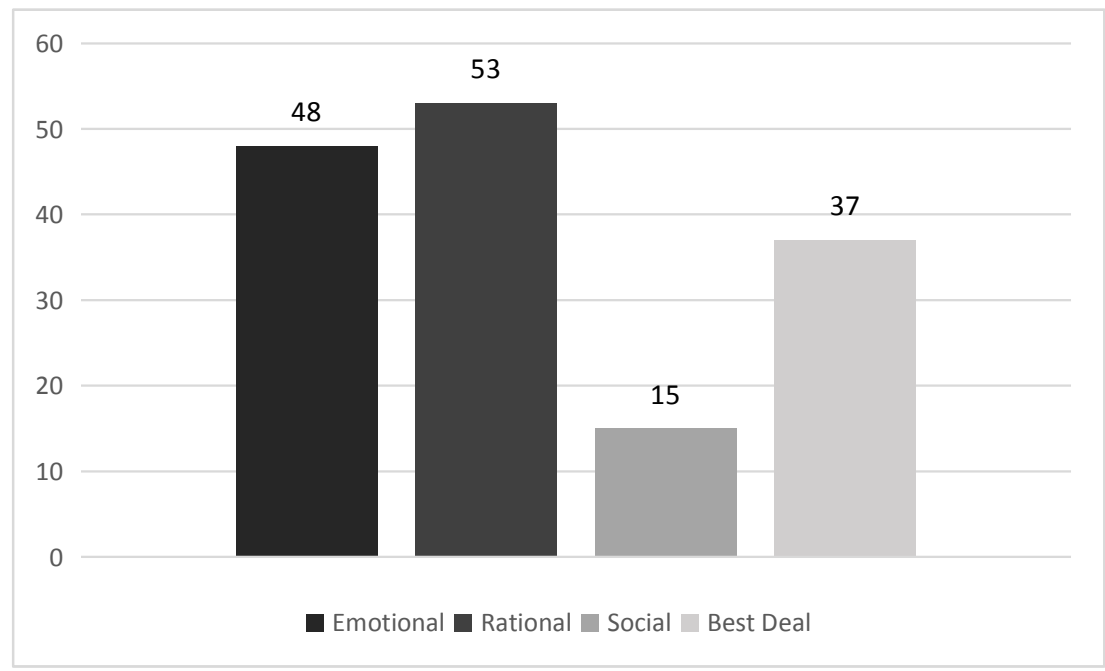

Source: authors' construction based on survey data

Fig. 6. Online shopping types ( $\%$ of respondents)

Authors point out that consumers do mostly rational shopping (53\%), which means that consumers search for alternatives and feedback before making a purchase online. That type is utilitarian shopping. But there is a very slight difference between rational and emotion online shopping (48\%). After reviewing the answers, authors found out that emotional shopping type (hedonic) are mostly common between women aged from 25 to 45 while men do mostly rational 
shopping. Also, a lot of customers do online shopping when there are the best deal options such as Black Friday, Cyber Monday, Christmas Sales etc.

Summarizing the results of the survey and the data available to the public, the authors of the paper reiterate that factors such as security, delivery options, quality-price relationship, special programmes, and communication itself are important for consumers when shopping online. When building marketing communication on the Internet it should be taken into account, that social networks and influencers have a deep control and can promote an online shop in a good way. Businesses need to remember that when it comes to communicating on the Internet, it must be timely planned. Because there is a high chance that the consumer will make a purchase with another merchant without waiting for an answer to question.

\section{Conclusions, proposals, recommendations}

1) According to the authors research communication with the consumer is important factor, moreover communication that is well-targeted and personalized really improves the consumer's interest and thoughts on the company.

2) Concluding the results of the survey and the data available to the public such factors as security, delivery options, quality-price relationship, special programmes, and communication itself are important for consumers when shopping online. That points are recommended to take into account while preparing message to consumers.

3) There can be mentioned a lot of determinants of online shopping such as information quality, design, customer service, transaction execution conditions, integrated marketing channels, online communities, bonuses, personalization levels, website security, added customer value, reliability and price advantage. It is therefore necessary to take these factors into account when drafting the message.

4) Authors research showed that customers are more likely to visit particular online store through social networks (48\%) and bloggers and influencers (41\%) can promote an online shop to customers and after their videos, posts or vlogs (video blogs) customers visit promoted shop or platform. So, social networks and influencers can be used as promoters to stimulate customers do shopping in a particular online store. Authors recommend to use influencers with different communication tools taking into account customer needs and feedback remembering that there are utilitarian and hedonic shopping styles.

5) The company's focus on personalized customer service is the cornerstone of its success for targeted customer interaction. This means, firstly, the use of a narrowly focused communication strategy and, second, the adaptation of the products and services developed to the needs and expectations of customers on the Internet.

6) In order to reach company's consumer in an online environment, it is necessary to use a variety of channels and tools to reach out to company's audience and to establish a dialogue with them. By not setting up such a link with the consumer in a timely manner, the Internet merchant runs into the risk that the consumer will find another alternative.

\section{Bibliography}

1. Ab Hamid, N.R., McGrath G.M., (2005). The Diffusion of Internet Interactivity on Retail Web Sites: A customer relationship model. Communications of the IIMA, No. 5 (2), pp. 35-46

2. Bilgihana, A., Bujisic, M. (2015). The Effect Of Website Features In Online Relationship Marketing: A Case Of Online Hotel Booking. Electronic Commerce Research and Applications, Volume 14, Issue 4, July-August, Pages 222-232 
3. Childers, T.L., Carr, C.L., Peck, J., Carson, S. (2001). Hedonic And Utilitarian Motivations For Online Retail Shopping Behaviour. Journal of Retailing, No. 774, pp. 511-535

4. Chiu, C.M., Wang, E.T., Fang Y.H., Huang H.Y. (2014). Understanding Customers' Repeat Purchase Intentions In B2C E-Commerce: The Roles Of Utilitarian Value, Hedonic Value And Perceived Risk. Information Systems Journal, No. 241, pp. 85-114

5. Cook, K. (2016). A Brief History of Online Advertising. Retrieved: https://blog.hubspot.com/marketing/history-of-online-advertising

6. Eurostat (2018). Retrieved: https://ec.europa.eu/eurostat

7. Floh, A., Madlberger, M. (2013). The Role Of Atmospheric Cues In Online Impulse-Buying Behaviour. Electronic Commerce Research and Applications, No. 126, pp. 425-439

8. Griffith, D.A., Krampf, R.F., Palmer, J.W. (2001). The Role Of Interface In Electronic Commerce: Consumer Involvement With Print Versus On-Line Catalogs. International Journal of Electronic Commerce, No. 5, pp. $135-154$

9. Hamari, J., Koivisto, J., Sarsa, H., (2014). Does Gamification Work? - A Literature Review Of Empirical Studies On Gamification. Proceedings of the 47th Hawaii International Conference on System Sciences, Hawaii, USA, January p. 6-9.

10. Hasan, B. (2016). Perceived Irritation In Online Shopping: The Impact Of Website Design Characteristics. Computers in Human Behavior. Volume 54, pp. 224-230

11. Hong, W., Thong, J.Y.L., Tam, K.Y. (2004). The Effects Of Information Format And Shopping Task On Consumers' Online Shopping Behavior: A Cognitive Fit Perspective. Journal of Management Information Systems, No. 213, pp. 149-184

12. Kawaf, F., Tagg S. (2017). The Construction Of Online Shopping Experience: A Repertory Grid Approach. Computers in Human Behavior. Volume 72, pp. 222-232

13. Kolesar, M.B., Galbraith, R.W. (2000). A Services-Marketing Perspective On E-Retailing: Implications For ERetailers And Directions For Further Research. Internet Research, No. 105, pp. 424-438

14. Lee, R., Sener, I., Mokhtarian, P., Handy, S. (2017). Relationships Between The Online And In-Store Shopping Frequency Of Davis, California Residents. Transportation Research Part A: Policy and Practice. Volume 100, pp. 40-52

15. Mekkamol, P., Piewdang, S., Untachai, S. (2013). Modeling E-CRM For Community Tourism In Upper Northeastern Thailand. Procedia - Social and Behavioral Sciences, No. 88, pp. 108-117

16. O'Brien, H.L. (2010). The influence of hedonic and utilitarian motivations on user engagement: the case of online shopping experiences. Interacting with Computers, No. 225, pp. 344-352

17. Semeradova, T., Vavrova, J. (2016). Using A Systemic Approach To Assess Internet Marketing Communication Within Hospitality Industry. Tourism Management Perspectives. Volume 20, October, pp 276-289

18. Wolfinbarger, M., Gilly, M.C. (2003). Etailq: Dimensionalizing, Measuring And Predicting Etail Quality. Journal of Retailing, No. 79, pp. 183-198 